The epigastric pain so often felt is probably referred from the downward drag of the overloaded caecum on the ascending mesocolon. When operating on cases under spinal anaesthesia I have often noticed that if any traction on the caecum was exerted the patient complained at once of sharp pain in the upper epigastrium, although the abdominal incision had been completely painless.

Putrefactive changes in the stagnant caecal contents and a chronic catarrhal inflammation of the mucosa no doubt play a part in producing both the local pain and the general toxaemia associated with the condition, and as a result of this inflammatory process one frequently sees a calcareous lymph gland along the ileo-colic artery in these cases.

It is a fact of some clinical importance that the more extreme degree of mobility, in which the hepatic flexure is so loosely attached that it drops on to the false pelvis in the erect posture and can be lifted well out of a right rectus incision, often produces less severe symptoms than those resulting from a mobile caecum and ascending colon, combined with a fixed hepatic flexure. The following case is a striking illustration of this :

Lieut.-Colonel D., aged 39, had suffered from an extreme degree of general enteroptosis for many years, with attacks of flatulent pain in the epigastrium, and sometimes in the right iliac fossa, which came on one to two hours after food. He had never been particularly constipated. In August, 1919, about an hour after lunch, he was suddenly seized with severe central abdominal pain and urgent vomiting, and presented every symptom of high intestinal obstruction. After eight hours the pain suddenly and spontaneously passed off, and when I saw him in conlsultation an hour later there was little to be macie out beyond a very marked habitus enteroptoticus, with easily e!icited splashing in both stomach and caecum. X-ray examination three days later showed a low-lying stomach and extremely mobile proximal colon, with the hepatic flexure lying down well below the iliac crest in the erect posture. No ulcer in the duodenum was detected by the radiologist. Exploratory operation conwas detected by the radiologist. Exploratory operation confirmed the $x$-ray findings as regards the extreme enteroptosis, but revealed a chronic ulcer in the first part of the duodenum,
with a flake of recently deposited fibrin on its peritoneal surface. I took the view that his previous symptoms had been due rather to the ulcer than to the enteroptosis. Accordingly, posterior gastro-enterostomy was done, the duodenal ulcer- infolded, and the appendix removed. Nothing at all was done for the mobile proximal colon, in view of the very general splanchmoptosis associated with it. The soundness of the procedure adopted was demonstrated by his subsequent progress. All the inligestion and flatulence, which had been for many years at thibutigestion enteroptosis, at once left him, and he has lived an active life without restrictions as to diet ever since.

In such a case, where the whole proximal colon with the hepatic flexure lies down on the pelvis, the bowel has more chance of propelling its contents normally than if the ascending colon and caecum are mobile and the hepatic flexure fixed and kinked. The case may be used also to point another moral. It should not too readily be assumed that a patient with a mobile proximal colon has no other lesion. Such patients are far more prone to develop appendicitis, gastric or duodenal ulcer, and gall stones than those whose alimentary canal has not had a lifelong struggle against gravity by reason of its abnor'mal mobility We do not yet know the precise manner in which gastric or duodenal ulcers or gall stones result from the caecal stagnation and catarrh associated with the mobile proximal colon. Nor for that matter do we entirely understand how hyperchlorhydria and gastric or duodenal ulcer result from chronic inflammation of the appendix. In both cases the clinical fact of their frequent association is well established but many gaps in our knowledge need to be filled by further pathological investigation. I think, however, that we know enough to reject quite confidently the mechanical theory recently advanced by Waugh, ${ }^{2}$ who suggests that the downward drag of the mobile ascending colon througl its mesocolon may produce destruction of tissue in the fixed second part of the duodenum and cause duodenal ulcer. Alternatively he suggests that where the duodenum and pyloric end of the stomach give way under the strain and become prolapsed, there is a tendency for the line of strain to be transferred to the lesser curva ture and cardiac end, producing an ulcer there. Witlout attempting to justify his very questionable hypothesis that aradual drag exerted on the peritoneal aspect of th duodenum or stomach would produce ulceration of their mucosa, he asserts that the second part of the duodenum is "the site that is most liable to ulceration." But the experience of most surgeons shows that ulcer is very common in the first part and relatively very uncommon in the second part of the duodenum. Mr. Waugh further remarks that "if the mode of formation of these ulcers has been rightly assumed ... a mobile ascending colon should be present in all cases." To one who can recall, as I can, a large number of cases of both gastric and duodenal ulcer in which it has been most difficult to expose the appendix through the ordinary upper rectus incision owing to normal fixation of the ascending colon, it will hardly appear that the mode of formation has been rightly assumed by Mr. Waugh.

\section{Operative Treatment.}

The ideal method of dealing with the mobile proximal colon is to fix it back in the right loin in the position that we have seen is the normal one for the orthograde primate. This may be done by the method of Coffey, ${ }^{3}$ or by the method recently described by Waugh. A considerable experience of the former method has taught me that it is often very difficult through the ordinary right rectus incision to fix the colon in a way that approximates to the normal, and there is the further difficulty that fixation by firm and unyielding scar tissue is a poor substitute for the firm but elastic support afforded by the normal peritoneal fixation of the colon. Accordingly I have latterly adopted the alternative course of reducing the load of the overburdened caecum and ascending colon by the simpler method of plication. After removal of the appendix, a continuous suture of fine thread picks up the anterior and lateral longitudinal taeniae from the base of the appendix, and is carried as far up the ascending colon as the dilatation appears to require. By this method the lumen of the caecum and ascending colon is permanently narrowed without in any way hampering the contraction of the bowel, and the clinical results have been in my experience very satisfactory.

The drastic operation of colectomy, either partial or total, with its considerable mortality, is one that should be reserved for cases with the most extreme disability, and should only be undertaken when the procedures devoid of any appreciable danger have failed to give relief.

REFERENCEs
1 Norley, Lancet. December 13 th, 1913. ${ }^{2}$ Waugh, Brit. Journ. Surg. vii, 1920, 343-383. '3 Coffey, Surgery, Gynaecology, and Obstetrics, $\mathbf{x v}$

\section{Khemarks}

\section{A CASE OF HEPATIC CIRRHOSIS ALLIED TO HANO'T'S DISEASE.}

Sir HUMPHRY ROLLESTON, K.C.B., M.D., F.R.C.P., EMERITUS PHYSICIAN, ST, GEORGE'S HOSPITAL; SENIOR PHYSICIAN, VICTORIA HOSPITAL FOR CHLDREN, S.W.,

STANLEY WYARD, M.D., M.R.C.P., PHISICIAN to OUT-PATIENTS AND PATEOLOGIST, VICTORIA HOSPITAL
FOR CHILDREN.

THIs case, though a single one, is perhaps worth publication on account of the failure to arrive at a correct diagnosis during life, the histological appẹarances of unilobular and intralobular cirrhosis, and the light recently thrown on such cases and on the problem of biliary cirrhosis by the experimental work of Peyton Rous and Lavimore, of the Rockefeller Institute for Medical Research.

A boy, aged 11 years, had influenza in December, 1918, and since then had never been well. In April, 1919, he became drowsy, and in May came under observation at the Victoria Hospital for Children. On May 23rd he was shown at the Section for the Study of Disease in Children, Royal Society of Medicine, as "a case for diagnosis," by Dr. E. A. Cockayne. ${ }^{1}$ At that time there was slight jaundice with a trace of albumin and of bile pigment in the urine, which was high coloured but free from excess of urobilin. The faeces were normal in colour and consistency. The blood count showed 6,100,000 red blood corpuscles per cubic millimetre, 6,400 leucocytes, with a differential count of polymorphonuclears 54 and mononuclears (46 per cent. The Wexterman reaction 46 per cent. The Wassermann reaction was negative. Therg. was an evening. pyrexia of $100^{\circ}$ to $101^{\circ} \mathrm{F}$. The boy was some. what wasted, with a slightly dark skin, which was free from any haemorrhages or spider-angiomas. There were no enlarged
glands. The abdomen was distended, but there were no dis- 
tended veins visible, and no actides. The liver was nuok enlarged; both lobes being smooth and free from tenderness, and the spleen was palpably enlarged. Dr. Cockayne considered that the condition was dae to abdominal tuberculosis, and with this view other speakers agreed, though the possibility of lymphadenoma and of post-influenzal hepatitis was raised; but Hanot's hypertrophic biliary cirrhosis was not suggested. The boy then went to a convalescent home, and on October 10th was readmitted to the Victoria Hospital and on October loth was readmitted to the Victoria Hospita. for Children, where he remained until his death on June 13th,
1920. On readmission it was noted that he had lost flesh, was 1920. On readmission it was noted that he had lost flesh, was still slightly jaundiced, ran an evening temperature of $101^{\circ}$ r.; had a rapid pulse rate, usually over 130 per minute, and a soft was purse-shaped, suggesting mitral disease, but there was no evidence of any intrathoracic growth. The leucocyte count of 6,200 per cubic millimetre showed 64 per cent. polymorphonuclears, 23.5 per cent. small lymphocytes, 7 per cent. large lymphocytes, 4 per cent. transitionals, and 1.5 per cent. hyalines. The Wassermann reaction was negative as before. T'he tbdomen was distended by the enlarged liver, measuring from $\$ 7$ to 29 inches according to varying flatulence, and showing jile pigment. over the surface. The until April, when the ile pigment. Ascites was not obvious until April, when the aundice became much more narked, and the patient, who inhe first quarter of the year had shown some general improve inent, although the temperature and pulse-rate had remained unuch the same, went downhill. Early in June diarrhoea witl incontinence supervened, and the ascites necessitated tapping (in June 8 th, 50 ounces of clear yellowish-green fiuid being lemoved. He then became semi-comatose, and died on ive 13th.

\section{Necropsy.}

The body is extremely emaciated and intensely jaundiced; he eyes are deeply sunken; the malar arches very prominent. '.here is no subcutaneons fat. No rigor mortis present. J'ongue, fauces, pharynx, tonsils, trachea, and bronchi are all normal; the cervical and mediastinal glands also. The pleura on the left side is adherent by recent easily broken down bands. There is no fluid. The right is free and also without fluid. Both lungs are healthy. The pericardial sac contains about $2 \mathrm{oz}$. of clear fluid, but there is no pericarditis. The heart is normal; the peritoneum contains about a pint of clear fluid. There are no adhesions and no inflammation. Stomach and small and large gut healthy. Adrenals and kidneys normal. The spleen weighs $11 \frac{1}{2} \mathrm{oz}$. It is soft and pulpy; there is no The spleen weighs $11 \frac{1}{2} \mathrm{oz}$. It is soft and pulpy; there is no
fibrosis. It is densely adherent to the stomach. The pancreas fibrosis. It is densely adherent to the stomach. The pancreas There is no evidence of new growth, but the organ appears extremely fibrotic.

The liver is much enlarged and weighs $3 \mathrm{lb} .6 \mathrm{oz}$. The surface is smooth, but the capsule wrinkled, as though the organ had recently undergone some shrinking in size. It is fairly but not extremely tough. The anterior edge is rounded, smooth, and regular. There is no perihepatitis, for the capsule is normal, without any thickening or opacity, and strips freely and cleanly. The surface, both externally and on section, is mottled with small green areas, each surrounded by strands of grey tissue, which similarly forms a zone about every vessel. The gall bladder is small and contains a little bile. Its mucosa is perfectly healthy. The cystic, hepatic, and common bile ducts are fectly healthy. The cystic, hepatic, and common bile ducts are normal in appearance. The hepatic and portat vessels
no abuormality. The brain and meninges are healthy.

Microscopic Lixamination.-Sections of the liver under the $m$ croscope show a well marked unilobular, together with an ereu more prominent intralobular cirrhosis. All the lobules are surrounded and separated from each other by wide strands of connective tissue from which narrower strands are given off and penetrate the individual lobules. Occasionally an islet of three to six liver cells lying in intimate contact with each other may be found, but such a condition is very rare, and practically every cell is isolated from its fellows by intervening connective tissue fibres. The fibres are coarse and the cell nuclei small and deeply staining; there is no evidence of any very active proliferation of these elements. The cells of the parenchyma. present all degrees of degeneration. As a rule, those in the outer zone of the lobule, in the neighbourhood of the portal vessels, show least change, then those about the central venules, while those in the intermediate zone are most affected. The while those in the intermediate zone are most affected. The last bave in many cases undergone extreme fatty. clegeneration; often the cell body is distended and completely occupied by a scattered throughout the cytoplasm. It stains readily with scattered throughout the cytoplasm. It stains readily with
osmic acid or Scharlach $R$. Here and there an area is found in osmic acid or Scharlach $R$. Here and there an area is found in almost : black pigment, which is certainly of biliary origin. These areas are situated about a branch of the portal vein, and are accompanied by a slight leucocytic infiltration of the connective tissue. Nowhere are the hepatic cells quite normal; many are completely destroyed, leaving nothing but a granular débris, others show some degree of karyolysis, while the rest vary much in size and shape, and the staining power of nucleus and cell body and the cy toplasm is finely granular. They have apparently passed into a state of exhaustion beyond the stage only in extremety fetw instances that any signs of mitosis can only in extremety few instances that any signs of mitosis can
be discovered. The blood vessels do not show any changes, but be discovered. The blood vessels do not show any changes, but are sometimes surrounded by a narrow zone of very mild (microscopically) extravasation of blood through one of the fibrous septa or amongst the parenchymal cells is found. It has teta impossible to discover either mast cells or plasma cells: The bile canaliculi are patent and free from any inflammatory change; there is no cholangitis nor pericholangitis. Careful and prolonged search, however, reveals some evidence of bile stasis, in addition to the pigmentation already mentioned. a bile capillary in its intralobular portion, either in the middle zone of the lobule or just as the capillary leaves the lobule and enters Glisson's capsule.

The indications of biliary stasis are thus by no means well marked. The areas of pigmentation are rarely met with; in them the pigmentation of individual cells is not extreme, and bile thrombi are very few in number. Pseado-bile canaliculi are very numerous throughout the perilobular connective tissue. They are for the most part solid columns of cubical or columnar cells, and few if any of them present a lumen. The spleen shows some excess of fibrous tissue elements, but sections of the pancreas do not reveal any abnormality whatever.

Remarks.

During the nine montlis of the boy's second stay in the hospital the diagnosis was uncertain; the rapid pulse rate (120 or over) and the mitral murmur at one time suggested that the large liver was cardiac, and that the condition might be that described by Hanot as hepatic asystole, in which the hepatic manifestations are more prominent than those of the primary cardiac lesion, as in the remarkable case recorded by one of us ${ }^{2}$ of a child aged $3 \frac{1}{2}$ years, regarded during life as primary sarcoma of the liver, with well marked dilatation of the subcutaneous abdomival veins, pointing to a collateral circulation between the superior and inferior venae cavae; the necropsy sliowed chronic venous engorgement of the liver only. Digitalis was therefore given a full trial in our case, but without any beneficial effect. New growth was also seriously suspected, but as time went on this possibility was narrowed down to some rare and innocent condition such as an angioma or a simple cyst; though exploration was often considered, the diagnosis never justified this. Hypertrophic biliary cirrhosis was not suspected.

The main clinical features of the case-namely, the large liver and spleen, jaundice, fever, chronicity, and absence of ascites until late in the course of the diseaseare, at any rate on paper, those of Hanot's lyypertrophic biliary cirrhosis, and histologically the unilobular and intralobular cirrhosis approach the changes described as characteristic of that disease. But both clinica!ly and histologically there is a want of prominence, if it may be so expressed, of the biliary element. The jaundice was slight until late in the course of the disease; but, as it was present throughout, the case cannot be regarded as one of the anicteric hypertrophic biliary cirrhosis described by the French. Then listologically evidence of biliary stasis, such as bile thrombi in the intralobular bile canaliculi or pigmentation of the lepatic cells, was extremely slight, and there was no inflammation of the small bile ducts. The type of cirrhosis corresponds fairly closely with that produced experimentally by Rous and Larimore. ${ }^{3}$ By ligature of the bile cluannels of one lobe of a rabbit's liver and of the branch of . the portal vein to the remainder of the organ, thus diverting all the portal blood into the loke with biliary stasis, these workers succeeded in producing an intralobular cirrliosis which they regarded as due to biliary stasis at the level of the intralobular bile ducts. The presence of a few bile thrombi in these vessels in our case indicates some degree of stasis at this le.vel. The unilobular cirrhosis, on the other hand, they resard as the outcome of stasis in the small bile ducts in Glisson's capsule at the margins of the lobule, where again a few bile thrombi existed in our case. Here also were sitrated those cells in which pigment had been deposited. The evidence of biliary stasis is thus most marked at the boundary between the lobules and Glisson's capsule, and it would consequently appear probable that the unilobular fibrosis was the first to make its appearance. Later, stasis was brought about further back within the lobules, and then the intralobular cirrhosis appeared. In our case the stasis was nowhere marked nor comparable in intensity with that produced in the extended and careful experimental research of Rous and Larimore, although the degree of fibrosis was practically the same. A possible explanation of this difference is afforded by the fact that in their rabbits the complicating factor of infection of the liver was always eliminated, whereas in our case this disturbing factor, though not proved, was rendered highly probable by the long-continaed fever. It is notewortly 
that the unilobular cirrhosis was that of Hanot's disease, but the intralobular was much more prominent than that regarded as characteristic of that condition.

1 Cockayne, Proc. Roy. Roc. Med. 1919, xii (Child. Dis.), 79. and L. D. Larimore, Journ. Exper. Med., Baltimore, 1920, xxxii, 249.

\section{THE INFLUENCE OF OVERCOOKING VEGE- TABLES IN CAUSING SCURVY AMONG CHILDREN.* \\ BY}

HARRIETTE CHICK, AND ELSIE J. DALYELE, LISTER INSTITUTE. BEIT MEMORIAL FELLOW.

(Report to the Lister Institute and to the Medical Research Council, London.)

IN April, 1919, 40 cases of scurvy occurred among the 64 children from 6 to 14 years of age under treatment for tuberculosis in the University Kinderklinik, Vienna (Professor C. v. Pirquet).

The first case, observed on April 12th, had pain in the jaws swollen, tender, and discoloured gums, and later swollen an tender knees. On April 14th two more cases were reported and developed symptoms of the same severity. Subsequently 37 fresh cases occurred, the last on April 28th; in all of these the symptoms were mild and confined to gums and jaws.

From April 18th to April 28th 45 lemons were provided dail for the 64 children in the section, and extra spinach "Kraut, and rew onions were added to the diet. The scorbutic patients


received also a preparation made by boiling pine tree needles in water. After April 28th extra supplies of fresh vegetables wer obtained. In all cases the symptoms subsided in ten days, an most in four or five days. In the majority of cases the weigh charts show a temporary arrest in growth during the attack but in no instance was there any evidence of a prolonged retardation.

The admirable arrangements of this hospital render the outbreak exceptionally favourable for study. A very accurate system of calculating food requirements has been elaborated by Professor v. Pirquet, and, as far as calories are concerned, each child has always received enough without any excess. The unusually complete records of diet which are kept as a routine measure permit of detailed analysis, and the average amount of each article of diet talien by each child can be accurately determined. Singularly full records are also kept of the growth in size and weight and the general condition of the patients, all of which were placed freely at our disposal by Professor v. Pirquet and his staff.

At the time of the outbreak there was no corresponding prevalence of scurvy in the general population, and the conditions which determined its onset have to be looked for inside the hospital and primarily in the food.

\section{Analysis of Diet.}

The articles of food consumed in the Tuberculosis Section of the Kinderklinik have been classified into :

(1) Those known to possess slight value or none for prevention of sourvy-tlour, oats, barley, eggs, cheese, condensed milk, lard and other fat, dry beans and peas.

(2) Those possessing marked antiscorbutic properties-green vegetables, potatoes, other root vegetables, fresh meat, and fresh milk.

The comparative values of the foodstuff under (2) are given in Table I below. The figures are based on quantitative experimental work carried out at the Lister Institute on guinea-pigs and monkeys. ${ }^{1}$ In many cases the

TABLE I.-Showing Comparative Antiscorbutic Value of Equivalent Weights.

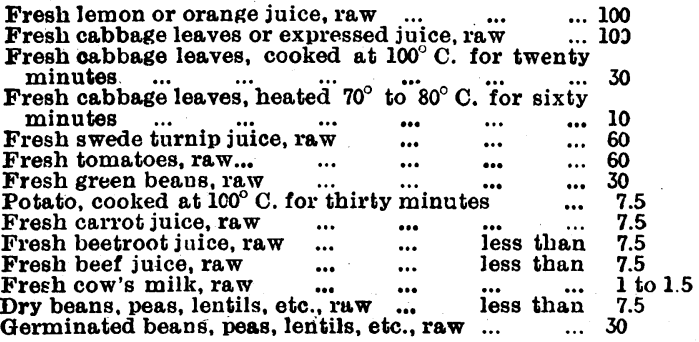

A more detailed account of this investigation is being publishel in Zeitschrift fiir Kinderkeilkunde. values have been confirmed by recent therapeutic trials in Vienna on infantile scurvy (Barlow's disease). The vialues of the fresh materials are, of course, much diminished by the ordinary procedure of cookery.

The possible influence of meat has been disregarded in the present investigation. Even when raw its antiscorbutic value is small and it must be consumed in very large amounts - for example, 500 grams and upwards per person daily ${ }^{2}$-if scurvy is to be prevented by its aigency alone. During the six months preceding this outbreak the weekly average per patient was less than 300 grams. We do not consider either that fresh milk has played any important part as an antiscorbutic in the present instance. At the best its antiscorbutic value is low, and owing to disor: ganized transport it was almost certainly heated twice before reaching the children. Up to the end of January, 1919, the average daily ration was never more than $250 \mathrm{c.cm}$. and during February and March this steadily declined to about $30 \mathrm{c.cm}$. More condensed milk was then used, but the value of this product is even less than that of fresh unheated milk. No fruit was taken. The average consumption of green vegetables, potatoes, and other root vegetables is given in Table II. The outstanding feature of this analysis is the deprivation of the most effective antiscorbutics after the middle of February. During the autumn of 1918 there appears to have been a generous provision of green vegetables, potatoes, etc. This was on the whole maintained during January, 1919, but there was a great falling off in February, which became still more marked in March.

These data appear to show clearly that a daily ration of about 80 grams root vegetables is insufficient to protect from scurvy, and we are of opinion that the marked shortage of all vegetables during the eight weeks from the middle of February to the middle of April was the immediate precipitating cause of the outbreak. If, however, this were the whole explanation, it is remarkable that such a short period of deprivation should cause widespread recognizable scurvy. For adults the necessary period has been fixed at from four to eight months, and oftener perhaps nearer the longer time. ${ }^{3}$ For children there appears to be no definite information beyond the fact that symptoms are rarely seen in infants less than 6 months old.4 It is not unlikely that the period for children is less than that for adults in correspondence with their greater metabolism, but there do not seem to be any grounds for taking it as shorter than four montlis.

Table II.-Average Daily Consumption by each Patient in Grams.

\begin{tabular}{|c|c|c|c|c|c|c|}
\hline Date. & 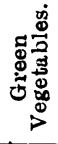 & 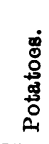 & 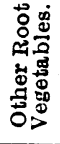 & 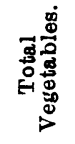 & $\begin{array}{r}M \\
\text { Fresb. }\end{array}$ & $\begin{array}{l}\text { Con- } \\
\text { densed. }\end{array}$ \\
\hline $\begin{array}{c}1918 . \\
\text { September-October ... }\end{array}$ & 102 & 114 & 15 & 231 & 188 & 30 \\
\hline $\begin{array}{c}\text { November-December . } \\
1919 .\end{array}$ & 62 & 110 & 62 & 234 & 225 & 16 \\
\hline 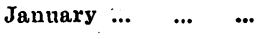 & 30 & 130 & 68 & 228 & 190 & 112 \\
\hline February (first half) ... & 0 & 55 & 92 & 147 ! & 33 & 215 \\
\hline February (second half) & 0 & 0 & 101 & $101)$ & & \\
\hline $\begin{array}{llll}\text { March } & \ldots & \ldots & \ldots\end{array}$ & 0 & 0 & 77 & 77 & 28 & 105 \\
\hline April (first fortnight) . & 12 & 1 & 53 & 66 & 0 & 80 \\
\hline
\end{tabular}

In the present instance the allowance of vegetables up to two months before the first cases appeared was more than 200 grams daily, which is not less than is usual in many private households during the winter, and may be expected to prove adequate for prevention. ${ }^{6}$ A similar allowance, 250 grams daily fresh vegetables, is a common ration for soldiers on active service, and instances must be numerous in which this amount has failed temporarily without appearance of scuiry in so short a period as eight weeks. In the present case, therefore, the antiscorbutic taken in the previous months should liave enabled these children to withstand eight weeks of comparative deficiency. It did not do so, and we are forced to conclude that while the supply of vegetables was adequate the supply of antiscorbutic was defective. 